\title{
Comparative Study between Sublay versus Onlay Mesh Repair in Treatment of Incisional Hernia
}

\author{
HAMED A. EL BADAWY, M.D.*; MOHAMMED S. ZARAD, M.D.* and MOHAMED A. DORBOK, M.Sc.** \\ The Department of General Surgery, Faculty of Medicine (for Girls), Al-Azhar University* and \\ Damanhour Medical National Institute, Damanhour, El Beheira**, Egypt
}

\begin{abstract}
Background: Incisional hernia is a common complication following laparotomy and is the most common indication for reoperation. However, the optimal approach for its repair is still a matter of debate.

Aim of Study: The aim of this study was to compare between sublay and onlay mesh repairs in treatment of incisional hernia regarding the operative technique and postoperative complications.

Patients and Methods: This prospective comparative study was conducted in General Surgery Department at Al-Zahraa University Hospital and Damanhour Medical National Institute in the period between October 2018 and April 2020. It included 120 patients with incisional hernia who were randomly divided into two equal groups: A (treated with sublay repair) and B (treated with onblay repair).

Results: The mean operative time in group A was 112.2 minutes and in group B was 98.2 minutes. The mean time of drain removal in group A was 5.9 days while in group B was 14.17 days. Seroma formation after drain removal was not recorded in any patients of group A while it occurred in 6 patients in group B (10\%). The other postoperative complications were comparable in both groups. During 6 months of follow-up, hernia recurrence occurred in 1 patient in group A $(1.7 \%)$ and in 3 patients in group B (5\%).

Conclusion: Sublay mesh repair of incisional hernia is a good alternative to onlay repair. It is applicable to all sites of incisional hernia with a low recurrence rate and acceptable complication rates.
\end{abstract}

Key Words: Incisional hernia - Mesh repair - Onlay - Sublay.

\section{Introduction}

INCISIONAL hernia is a ventral hernia occurring through an operative scar. It occurs because of failure of healing of the lines of closure of abdominal wall, except the skin, following abdominal surgery [1].

Correspondence to: Dr. Mohamed A. Dorbok, E-Mail: mead12091987@gmail.com
Incisional hernia is a common complication following laparotomy occurring in $2-11 \%$ of patients and is the most common indication for reoperation by a 3:1 ratio over adhesive small bowel obstruction [2].

Incisional hernia repair can be done by either an open or a laparoscopic technique. The open technique can be a simple suture repair or a mesh repair [3].

Open mesh repair is the standard procedure for incisional hernia repair. The mesh can be placed between the subcutaneous tissues of the abdominal wall and the anterior rectus sheath (onlay repair) as well as it can be placed in the preperitoneal space or in the retromuscular space created between the rectus muscle and posterior rectus sheath (sublay repair) [4].

The aim of this study was to to compare between sublay and onlay mesh repairs in treatment of incisional hernia regarding the operative technique and post-operative complications.

\section{Patients and Methods}

This prospective study was done on a consecutive sample of 120 patients who were admitted to Al-Zahraa University Hospital and Damanhour Medical National Institute and satisfied the inclusion and exclusion criteria to be enrolled in the study during the period between October 2018 and April 2020. All patients participated in the study after taking informed consent according to the ethical committee of both hospitals.

\section{Inclusion criteria:}

Uncomplicated incisional hernia, fitness for surgery and patients' agreement to undergo the 
operation with either the sublay or the onlay methods of repair.

\section{Exclusion criteria:}

Complicated incisional hernia (inflamed, obstructed or strangulated), uncompensated heart or lung diseases, hemorrhagic disorders and intraoperative intestinal injury necessitating no mesh placement.

All patients were subjected pre-operatively to: Detailed history taking, thorough clinical examination and routine pre-operative laboratory investigations including: Complete Blood Count (CBC), coagulation profile, random blood sugar, liver and kidney function tests. Abdominal ultrasonography was done routinely to exclude any intraabdominal pathology. Abdominal Computed Tomography (CT) was done only if needed. Chest plain X-ray was done in patients with history of smoking, bronchial asthma or clinical signs of chest troubles. Electrocardiography (ECG) and Echocardiography were done in patients above 40 years. The 120 patients were randomly divided into two equal groups (A and B). Patients in group A were treated with sublay repair, whereas patients in group B were treated with onlay repair. All cases were done under general anaesthesia while patients placed in the supine position. A single dose of broad spectrum antibiotic was given at induction of anaesthesia.

\section{Surgical techniques:}

In group A (sublay repair): An elliptical skin incision was made including the old scar. The sac was dissected and delineated. The defect, most often in the midline, was opened along the linea alba. Adhesions were divided and hernial contents were reduced into the abdomen. The posterior rectus sheath was incised near the linea alba and the retromuscular space was dissected using a combination of blunt and sharp dissection laterally

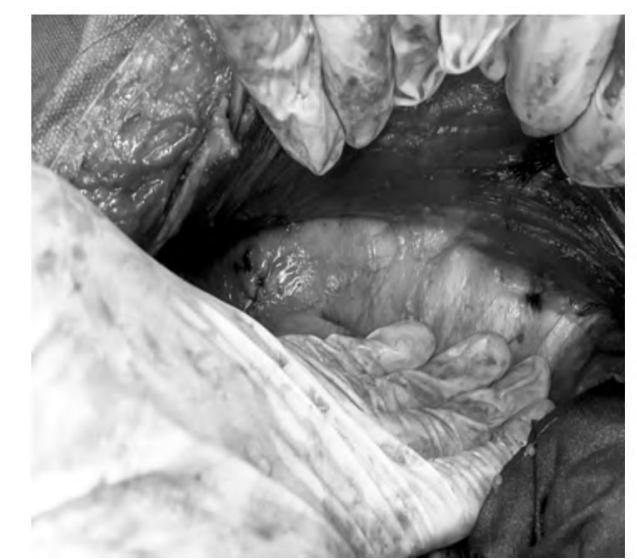

Fig. (1): Dissection of the retromuscular space. to the linea semilunaris on one side and then on the other side Fig. (1). Intercostal nerves and vessels were carefully identified and preserved. The dissection was extended cranially and caudally for 5 $\mathrm{cm}$ above and below the edge of the defect. The posterior rectus sheath was closed in the midline by continuous sutures Fig. (2).

A polypropylene mesh was tailored to the required dimensions and placed in the plane created Fig. (3). The mesh was secured with interrupted $2 / 0$ polypropylene sutures placed $5 \mathrm{~cm}$ apart at the limits of the dissection to the overlying rectus muscle and anterior rectus sheath. A suction drain was placed over the mesh. The anterior rectus sheath is closed without tension by continuous no. 1 polypropylene sutures. The subcutaneous tissue and skin were closed.

When it was not possible to close the anterior rectus sheath without tension, an external component separation was done either unilaterally or bilaterally by dissecting the subcutaneous fat off the anterior rectus sheath to beyond the linea semilunaris and making a vertical incision in the external oblique aponeurosis $1-2 \mathrm{~cm}$ lateral to the lateral edge of the rectus muscle and separating the external oblique aponeurosis from the internal oblique muscle as far laterally as the midaxillary line, then closing the anterior rectus sheath in the midline and fixing another mesh over the aponeurosis with its lateral edge(s) fixed to the lateral incised edge(s) of the external oblique aponeurosis Fig. (4).

In lateral incisional hernias, the dissection was done in the plane between the external oblique and internal oblique muscles and the mesh was fixed in the dissected space. Only when the defect was situated close to the bone, preperitoneal dissection and mesh placement was done to provide adequate mesh overlap Fig. (6).

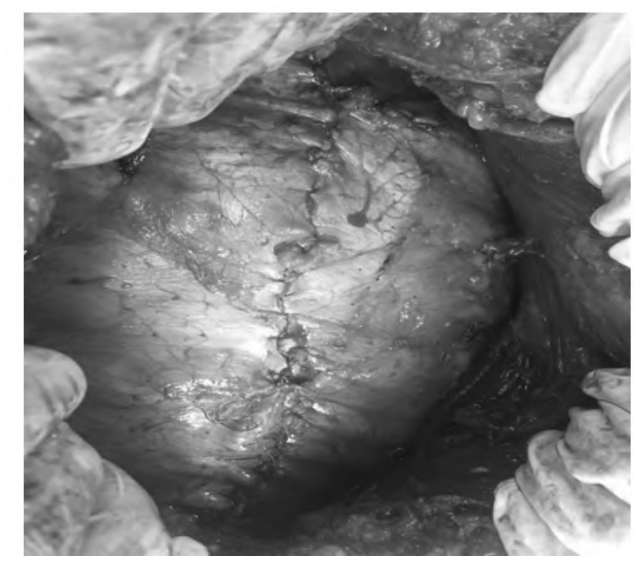

Fig. (2): Posterior rectus sheath closed in midline. 


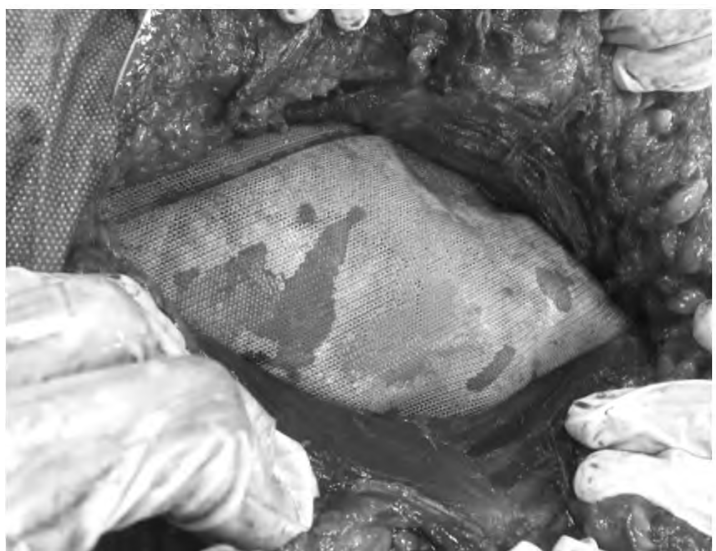

Fig. (3): The mesh positioned in the subrectal space.

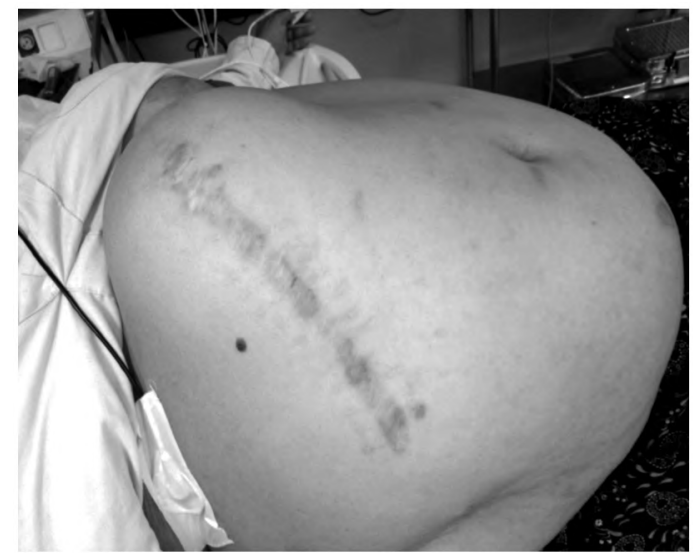

Fig. (5): Non-midline incisional hernia post-cholecystectomy.

In group $B$ (onlay repair): The skin incision was made in the same manner as in the sublay repair. Dissection was performed at the subcutaneous plane for at least $5 \mathrm{~cm}$ around the defect. The sac was dissected, the contents were reduced back into the abdomen, and the excess sac was excised. The hernial defect was closed in the midline by continuous no. 1 polypropylene sutures Fig. (7).

The mesh was stretched over the whole dissected aponeurosis with $5 \mathrm{~cm}$ overlap around the

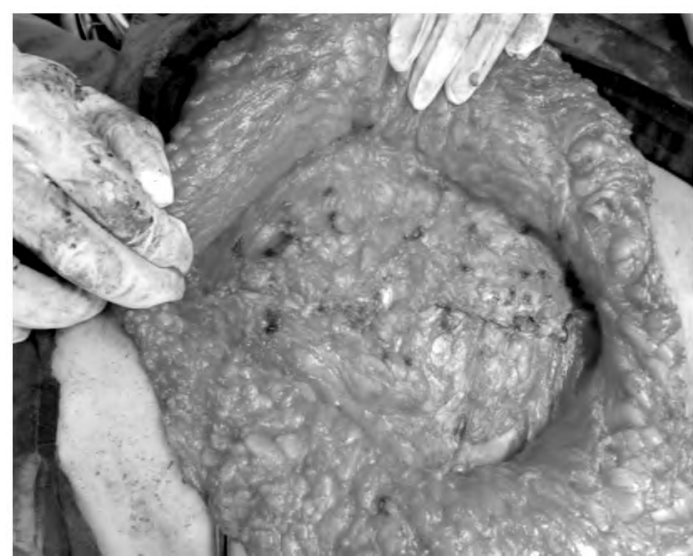

Fig. (7): The subcutaneous plane dissected and the hernial defect closed.

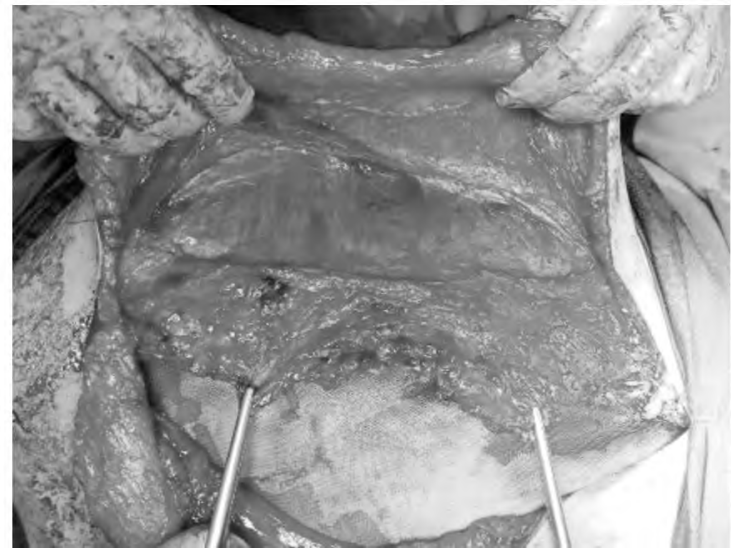

Fig. (4): External component separation.

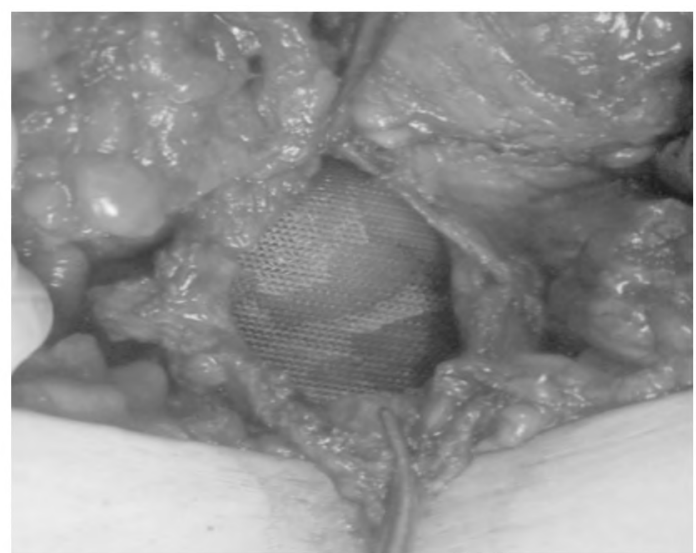

Fig. (6): Preperitoneal mesh placement in a case of lateral incisional hernia.

repaired defect in all directions. The mesh was fixed to the underlying aponeurosis with $2 / 0$ polypropylene sutures. Continuous sutures were used for the edges of the mesh and multiple scattered simple sutures were used on its surface taking good bites of the mesh and the aponeurosis Fig. (8). A suction drain was left in front of the mesh. The subcutaneous tissue and skin were closed. In lateral incisional hernias, the same technique was used.

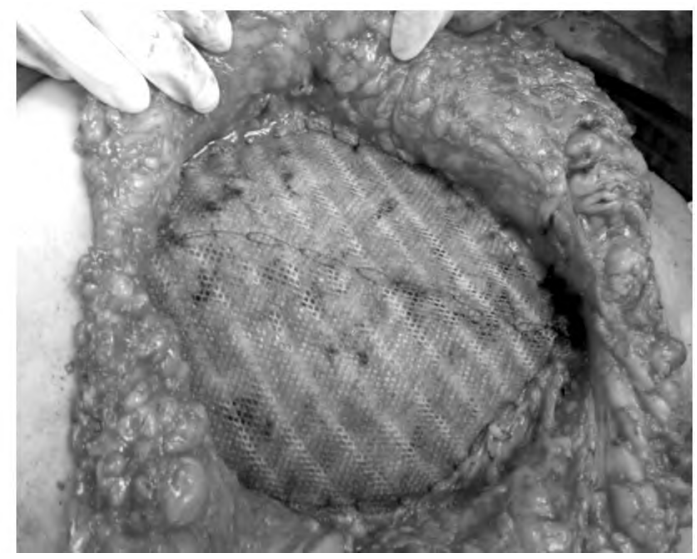

Fig. (8): Mesh fixation over the external oblique aponeurosis. 
The following operative data was recorded: The site of previous incision upon which the hernia developed, the type of mesh repair and the duration of surgery (from incision to skin closure).

\section{Post-operative management:}

Patients were kept nil by mouth on intravenous fluids till regaining of bowel activity in the form of audible bowel sounds and passing of flatus or motion. The patients were encouraged for early gradual ambulation. All patients received postoperative analgesia. Intravenous antibiotics were given twice daily for 2 days post-operatively and were continued only if infection was encountered. Each patient was assessed in the post-operative period before discharge for early post-operative complications as: Subcutaneous heamatoma, wound infection and flap necrosis.

If there were no early complications, the patient was discharged after tolerating per oral nutrition and achieving sufficient pain relief. The duration of postoperative hospital stay was recorded. At discharge, patients were advised to avoid smoking and carrying heavy weights.

Antibiotics were continued orally up to 14 days unless infection occurred. Drains were removed when the daily drainage decreased to below $20 \mathrm{cc}$. The time of drain removal was recorded.

All patients were asked to follow-up every week for one month then every month for 6 months to evaluate the outcome of the operation and detect the delayed post-operative complications as wound sinus, adhesive intestinal obstruction and recurrence of hernia.

The two techniques were evaluated on the basis of the following parameters: Operative time, postoperative hospital stay, time of drain removal, incidence of seroma formation after drain removal, wound infection, recurrence rate, other complications e.g. sinus formation, intestinal obstruction and enterocutaneous fistula.

\section{Statistical analysis:}

Data were fed to the computer and analyzed using IBM SPSS software package version 20.0 (Armonk, NY: IBM Corp). Qualitative data were described using numbers and percentages. The Kolmogorov-Smirnov test was used to verify the normality of distribution. Quantitative data were described using range (minimum and maximum), mean, standard deviation and median.

The used tests were: Student $t$-test for normally distributed quantitative variables, Mann Whitney test for abnormally distributed quantitative variables and Fischer exact test for qualitative (categorical) variables. In all these tests, the significance of the obtained results was judged at the $5 \%$ level ( $p$ $\leq 0.05)$.

\section{Results}

The ages of the 120 patients ranged from 24 to 64 years with a median age of 46 . The mean age of the cases was 44.85 .46 patients $(38.3 \%)$ were males while $74(61.7 \%)$ were females. The male to female ratio was $1: 1.6$. The highest incidence $(42.5 \%)$ was among patients with an age range from 40 to 50 years, while the lowest incidence $(4.2 \%)$ was in patients with an age of 60 years or more (Table 1).

In 88 patients $(73.3 \%)$ the incisional hernia followed a midline incision, in 15 patients $(12.5 \%)$ followed a subcostal incision, in 8 patients $(6.7 \%)$ followed a Pfannenstiel incision, in 7 patients (5.8\%) followed a McBurney incision and in 2 patients $(1.7 \%)$ followed a paramedian incision (Table 2).

Table (1): Patients' demographic data.

\begin{tabular}{|c|c|c|c|c|c|c|}
\hline & \multicolumn{2}{|c|}{ Group A $(n=60)$} & \multicolumn{2}{|c|}{ Group B $(n=60)$} & \multicolumn{2}{|c|}{ Total $(n=120)$} \\
\hline & No. & $\%$ & No. & $\%$ & No. & $\%$ \\
\hline \multicolumn{7}{|l|}{ Age: } \\
\hline $20-<30$ & 7 & 11.7 & 4 & 6.7 & 11 & 9.2 \\
\hline $30-<40$ & 11 & 18.3 & 13 & 21.6 & 24 & 20 \\
\hline $40-<50$ & 27 & 45 & 24 & 40 & 51 & 42.5 \\
\hline $50-<60$ & 14 & 23.3 & 15 & 25 & 29 & 24.1 \\
\hline$\geq 60$ & 1 & 1.7 & 4 & 6.7 & 5 & 4.2 \\
\hline Min.-Max. & \multicolumn{2}{|c|}{$27-61$} & \multicolumn{2}{|c|}{$24-64$} & \multicolumn{2}{|c|}{$24-64$} \\
\hline Mean \pm SD & \multicolumn{2}{|c|}{$44.45 \pm 8.82$} & \multicolumn{2}{|c|}{$45.25 \pm 9.29$} & \multicolumn{2}{|c|}{$44.85 \pm 9.03$} \\
\hline Median & \multicolumn{2}{|c|}{45.5} & \multicolumn{2}{|c|}{46} & \multicolumn{2}{|c|}{46} \\
\hline \multicolumn{7}{|l|}{ Sex: } \\
\hline Male & 24 & 40 & 22 & 36.7 & 46 & 38.3 \\
\hline Female & 36 & 60 & 38 & 63.3 & 74 & 61.7 \\
\hline
\end{tabular}

Table (2): The previous incision upon which the hernia developed.

\begin{tabular}{|c|c|c|c|c|c|c|}
\hline \multirow{2}{*}{$\begin{array}{l}\text { Original } \\
\text { incision }\end{array}$} & \multicolumn{2}{|c|}{ Group A $(n=60)$} & \multicolumn{4}{|c|}{ Group B $(n=60)$ Total $(n=120)$} \\
\hline & No. & $\%$ & No. & $\%$ & No. & $\%$ \\
\hline Midline & 45 & 75 & 43 & 71.7 & 88 & 73.3 \\
\hline Subcostal & 8 & 13.4 & 7 & 11.7 & 15 & 12.5 \\
\hline Pfannenstiel & 5 & 8.3 & 3 & 5 & 8 & 6.7 \\
\hline McBurney & 2 & 3.3 & 5 & 8.3 & 7 & 5.8 \\
\hline Paramedian & 0 & 0 & 2 & 3.3 & 2 & 1.7 \\
\hline
\end{tabular}

Emergency laparotomy was the most frequent risk factor for development of incisional hernia found in $67.5 \%$ of the cases, the next was history of wound infection that was present in 55\% of the patients, history of post-operative vomiting and distension was present in $48.3 \%$ of the patients. Other risk factors were obesity (32.5\%), anemia 
(27.5\%), COPD and bronchial asthma (20.8\%), diabetes mellitus $(15 \%)$ and hypoalbuminemia (5.8\%) (Table 3).

Table (3): Risk factors.

\begin{tabular}{lcccccc}
\hline \multirow{2}{*}{ Risk factors } & $\begin{array}{c}\text { Group A } \\
(\mathrm{n}=60)\end{array}$ & $\begin{array}{c}\text { Group B } \\
(\mathrm{n}=60)\end{array}$ & \multicolumn{2}{c}{$\begin{array}{c}\text { Total } \\
(\mathrm{n}=120)\end{array}$} \\
\cline { 2 - 7 } & No. & $\%$ & No. & $\%$ & No. & $\%$ \\
\hline - Emergency laparotomy & 39 & 65 & 42 & 70 & 81 & 67.5 \\
- Wound infection & 35 & 58.3 & 31 & 51.7 & 66 & 55 \\
- Post-operative vomiting and & 26 & 43.3 & 32 & 53.3 & 58 & 48.3 \\
distension & & & & & & \\
- Obesity (BMI* $>30)$ & 18 & 30 & 21 & 35 & 39 & 32.5 \\
- Anemia & 15 & 25 & 18 & 30 & 33 & 27.5 \\
- COPD $†$ and bronchial asthma & 14 & 23.3 & 11 & 18.3 & 25 & 20.8 \\
- Diabetes mellitus & 11 & 18.3 & 7 & 11.7 & 18 & 15 \\
- Hypoalbuminemia & 3 & 5 & 4 & 6.7 & 7 & 5.8 \\
\hline
\end{tabular}

*: Body mass index

$\dagger$ : Chronic obstructive pulmonary disease.

The mean operative time in group A was 112.2 minutes ranging from 82 to 150 minutes while in group B it ranged from 70 to 135 minutes with a mean value of 98.2. There was a statistically significant difference between both groups regarding the operative time $(p<0.05)$ (Table 4$)$.

The mean duration of post-operative hospital stay in group A was 3.65 days ranging from 1 to 24 days while in group B, it ranged from 1 to 15 days with a mean value of 4.32 . There was no statistically significant difference between both groups regarding the duration of post-operative hospital stay (Table 4).

The mean time of drain removal in group A was 5.9 days ranging from 4 to 11 days while in group B it ranged from 8 to 21 days with a mean value of 14.17 . There was a statistically significant difference between both groups regarding the time of drain removal $(p<0.05)$ (Table 4$)$.

Table (4): Operative time, post-operative hospital stay and time to remove the drains.

\begin{tabular}{|c|c|c|c|c|}
\hline & $\begin{array}{l}\text { Group A } \\
(n=60)\end{array}$ & $\begin{array}{c}\text { Group B } \\
(\mathrm{n}=60)\end{array}$ & $\begin{array}{c}\text { Test of } \\
\text { significance }\end{array}$ & $\begin{array}{c}p- \\
\text { value }\end{array}$ \\
\hline $\begin{array}{l}\text { Operative time: } \\
\text { Min.-max. } \\
\text { Mean } \pm \text { SD. } \\
\text { Median }\end{array}$ & $\begin{array}{c}82-150 \\
112.2 \pm 21.42 \\
105\end{array}$ & $\begin{array}{c}70-135 \\
98.2 \pm 18.80 \\
98\end{array}$ & $\begin{array}{c}\text { Student } \\
t \text {-test }\end{array}$ & $<0.001^{*}$ \\
\hline $\begin{array}{l}\text { Post-operative } \\
\text { hospital stay: } \\
\text { Min.-max. } \\
\text { Mean } \pm \text { SD. } \\
\text { Median }\end{array}$ & $\begin{array}{c}1-24 \\
3.65 \pm 3.64 \\
3\end{array}$ & $\begin{array}{c}1-15 \\
4.32 \pm 3.71 \\
3\end{array}$ & $\begin{array}{l}\text { Mann } \\
\text { Whitney } \\
\text { test }\end{array}$ & 0.384 \\
\hline $\begin{array}{l}\text { Time to remove } \\
\text { the drains: } \\
\text { Min.-max. } \\
\text { Mean } \pm \text { SD. } \\
\text { Median }\end{array}$ & $\begin{array}{c}4-11 \\
5.90 \pm \frac{1}{5}\end{array}$ & $\begin{array}{c}8-21 \\
14.17 \pm 5.19 \\
13\end{array}$ & $\begin{array}{l}\text { Mann } \\
\text { Whitney } \\
\text { test }\end{array}$ & $<0.001 *$ \\
\hline
\end{tabular}

In (Table 5), the 2 groups were compared regarding the post-operative complications. Flap edge necrosis occurred in 2 patients in group A $(3.3 \%)$ and in 4 patients in group B $(6.7 \%)$. They were managed by excision of the necrotic edge followed by delayed primary closure.

Wound infection occurred in 2 patients in group A $(3.3 \%)$ and in 7 patients in group B $(11.7 \%)$. They showed good response to conservative treatment with broad spectrum antibiotics and frequent dressings. Mesh infection necessitating its removal occurred in 1 patient in group A (1.7\%) and in 2 patients in group B (3.3\%).

Seroma formation after drain removal was not recorded in any patient of group A while it occurred in 6 patients in group B (10\%). In 4 out of these 6 cases, the seroma resolved spontaneously within 1 to 2 months without sequelae. In the other 2 cases, the seroma was large and persistent, so that it was treated by repeated aspiration under complete aseptic conditions until complete evacuation.

Table (5): Post-operative complications.

\begin{tabular}{lccccccc}
\hline \multirow{2}{*}{$\begin{array}{l}\text { Post-operative } \\
\text { complications }\end{array}$} & $\begin{array}{c}\text { Group A } \\
(\mathrm{n}=60)\end{array}$ & $\begin{array}{c}\text { Group B } \\
(\mathrm{n}=60)\end{array}$ & $\begin{array}{c}\text { Test of } \\
\text { signifi- } \\
\text { cance }\end{array}$ & $\begin{array}{c}p \text { - } \\
\text { value }\end{array}$ \\
\cline { 2 - 5 } & No. & $\%$ & No. & $\%$ & & \\
\hline Flap necrosis & 2 & 3.3 & 4 & 6.7 & Fisher & 0.679 \\
Wound infection & 2 & 3.3 & 7 & 11.7 & Exact & 0.163 \\
Mesh infection and removal & 1 & 1.7 & 2 & 3.3 & test & 1.000 \\
Seroma formation & 0 & 0 & 6 & 10 & & $0.027^{*}$ \\
Enterocutaneous fistula & 1 & 1.7 & 0 & 0 & & 1.000 \\
Intestinal obstruction & 1 & 1.7 & 1 & 1.7 & & 1.000 \\
Chronic sinus tract & 0 & 0 & 3 & 5 & & 0.244 \\
Recurrence & 1 & 1.7 & 3 & 5 & & 0.619 \\
\hline
\end{tabular}

$p: p$-value for comparing between the studied groups

$*$ : Statistically significant at $p \leq 0.05$.

Enterocutaneous fistula occurred in 1 patient in group A (1.7\%). This patient was operated for a midline incisional hernia. Post-operatively, the patient had ileus, abdominal distension and vomiting. Also, there were episodes of cough. This resulted in wound dehiscence and in the 10 th postoperative day, intestinal content was noticed coming out of the wound. That was attributed to contact of the mesh to the intestine resulting in erosion and perforation. The patient was prepared for reoperation in which resection of the perforated small bowel segment was done followed by primary anastomosis, the mesh was completely excised and the midline was closed with non-absorbable sutures after insertion of an intraperitoneal drain. The patient improved and was discharged from the hospital after staying for 24 days. Enterocutaneous fistula did not occur in any patient of group B. 
One patient in each group had an attack of adhesive intestinal obstruction during the followup period. They improved with conservative management (nasogastric tube, nil per mouth and intravenous fluids).

Chronic stitch sinus occurred in 2 cases in group B $(3.3 \%)$. They were treated by exploring the sinus and removing the offending suture material. No cases of chronic sinus tract were seen in group A.

During the follow-up period, hernia recurrence occurred in 1 patient in group A $(1.7 \%)$ and in 3 patients in group B (5\%). In 3 out of these 4 cases, hernia recurrence occurred after removal of the infected mesh.

There was a statistically significant difference between both groups regarding seroma formation after drain removal $(p<0.05)$ but there was no significant difference regarding flap edge necrosis, wound infection, mesh infection and removal, enterocutaneous fistula, adhesive intestinal obstruction, chronic sinus tract and hernia recurrence.

\section{Discussion}

Incisional hernia is the most common complication following laparotomy and is still representing a challenge to surgeons due to high recurrence rate and morbidity [5]

Mesh fixation technique is the gold standard procedure for incisional hernia repair. Restriction to the principles of repair reduces the post-operative complications and recurrence rates. These principles include: Strict aseptic technique, tension free repair, repair of the whole previous surgical scar, closure of the fascial defect with non-absorbable sutures taking good bites with narrow intervals, making at least $5 \mathrm{~cm}$ mesh overlap of the hernial defect in all directions and prophylactic use of antibiotics post-operatively [6]

There is no consensus about the ideal location for mesh placement in open incisional hernia repair [7].

This study aimed to compare the outcomes between two methods of mesh placement techniques (onlay \& sublay) in patients who underwent open incisional hernia repair.

In the present study, the mean age of the studied cases was 44.85 years. The highest incidence $(42.5 \%)$ was among patients with an age range from 40 to 50 years. This is similar to the results obtained by Kumar et al., in a study on 50 patients in 2018. They found that the peak incidence of incisional hernia was between 40 and 50 years of age. The mean age of their cases was 43.98 years [8]. In their study on 161 patients of incisional hernia, Venclauskas et al., reported that the majority of the cases were in their 6 th decade with the mean age was 54.7 years [9].

In our study, the male to female ratio was 1:1.6. This shows a slight increase in the incidence of incisional hernia in the female gender. The higher percentage of incisional hernia in females might be due to laxity of abdominal wall muscles after multiple pregnancies and also increased incidence of obesity in females [10]. This is similar to the results obtained by Kurzer et al., in their study of the long term results of sublay mesh repair of incisional hernia in 125 patients. They found that the male to female ratio was 1:1.5 [11]. In contrast, Ahmed and Mehboob reported that incisional hernia is more common in males with the male to female ratio was 1.8:1 [6].

In the present study, $73.3 \%$ of the cases developed incisional hernia through a midline incision. This coincides with the results of Singh et al. who found that midline incision was the original incision upon which the hernia developed in $85 \%$ of the cases [10]. Ahmed and Mehboob reported that in $64.6 \%$ of their cases, incisional hernia developed on top of a midline incision [6]. In the present study, the most frequent associated risk factors for development of incisional hernia were emergency laparotomy $(67.5 \%)$ and history of wound infection $(55 \%)$. In their study on 60 cases of incisional hernia, Kapoor and Hassan reported that in $87 \%$ of the cases, the original operation was done on an emergency basis due to peritonitis or intestinal obstruction [12]. Singh et al., found that the most common risk factor for development of incisional hernia was the occurrence of wound infection after the previous surgery that was found in $46.67 \%$ of their cases [10]. Similar to our study, Garg et al., found that obesity, smoking, chronic cough, diabetes mellitus and anemia were important risk factors for incisional hernia development [13] .

In our study, the operative time was significantly longer in the sublay group than in the onlay group. This is due to the time consumed in dissecting the retrorectal or preperitoneal space. Venclauskas et al., reported that, the mean operative time in the sublay group was 168.4 minutes while in the onlay group was 135.8 minutes [9]. Saber and Emad reported that, the mean operative time in the sublay group was 93.2 minutes while in the onlay group 
was 67.0 minutes [14]. These 2 studies show wide variation regarding the operative time in each group but these results agree with each other and with our results that the sublay repair took significantly longer time than the onlay repair to be done. In contrast, Ibrahim et al., found that there was no significant difference between the 2 groups regarding the operative time with the mean values of the operative time in the sublay and onlay groups were $89.5 \& 83.4$ minutes respectively [15]

Regarding the post-operative hospital stay, there was no statistically significant difference between both groups in our study. This is consistent with the results of Ibrahim et al., who found that the mean postoperative hospital stay in the onlay group was longer than that in the sublay group and as in our study, this difference was not statistically significant. The mean duration of hospital stay in the onlay group was 4.63 days, whereas it was 2.62 days in the sublay group $(p=0.063)$ [15]. In another study conducted by Shah et al., in 2019 and included 180 cases, they reported that the mean duration of post-operative hospital stay in the onlay group was 6.68 days, whereas it was 4.8 days in the sublay group. This difference was statistically significant as the duration of hospital stay was more than 5 days in $92.2 \%$ of cases of the onlay group but only in $12.2 \%$ of those of the sublay group [16]. On the other hand, Godara et al., found that the duration of post-operative hospital stay was significantly longer in the sublay group than in the onlay group. The mean duration of hospital stay in the sublay group was 6.8 days, whereas it was 4.6 days in the onlay group $(p<0.001)$ [17]

As regard the time of drain removal, we found that it was significantly longer in the onlay group than in the sublay group. Sevinç et al., in 2018 reported that the drains were removed when the daily outcome was below $50 \mathrm{ml}$. The mean drain removal time was 5.4 days in the onlay group and 3.2 days in the sublay group $(p=0.001)$ [7]. This agrees with our results that there was a significant difference between the 2 groups regarding the time of drain removal but differs in that the drainage time was shorter than in our study especially in the onlay group. The difference between our study and the study of Sevinç et al., regarding when to remove the drains (when the daily discharge become less than $20 \mathrm{ml}$ in our study and $50 \mathrm{ml}$ in theirs) might have contributed to the difference in the results of drainage time between the 2 studies. In contrast to our results, Godara et al., found that there was no significant difference between the 2 groups regarding the time of drain removal. In $84 \%$ of cases of the sublay group and $88 \%$ of cases of the onlay group, drains were removed after 2 days only [17].

Seroma formation after drain removal is a common complication after incisional hernia repair. In many previous studies, the rate of seroma formation after the onlay repair is much more than that after the sublay repair with statistical significant distribution [14]. In the onlay repair, many blood vessels are transected during the required wide mobilization of subcutaneous tissue flaps. Also, the insertion of mesh in the preaponeurotic plane temporarily establishes an effective barrier between the circulatory system of the subcutaneous tissues and that of the deeper parietal layers [14]. In the sublay repair, the retromuscular space is an already existing anatomical plane, requiring no dissection, and the bare posterior surface of the rectus muscles is rich in lymphatics capable to absorb any collecting seroma [18].

In our study, the incidence of seroma formation after drain removal was significantly higher in the onlay group. This is consistent with the results of Sevinç et al., who reported seroma formation after drain removal in $14 \%$ of cases in the onlay group and in only $2 \%$ in the sublay group $(p=0.027)$ [7] Ahmed and Mehboob reported a higher incidence of seroma formation after drain removal but still much less in the sublay group than in the onlay group with statistically significant difference ( $p=$ 0.001 ). The incidence was $20 \%$ and $4.6 \%$ in onlay and sublay groups respectively [6]

Onlay technique is associated with a higher rate of wound infection that remains one of the most common complications of this technique with reported incidence rate ranging between $6-12 \%$ [19]. There is no clear explanation to this relatively high incidence of wound infection in a procedure categorized as clean surgery. However, the presence of the mesh in the subcutaneous plane, the fact that those patients are commonly obese, the prolonged subcutaneous drainage and the accumulation of seroma may represent reasonable explanations [18].

In our study, wound infection was also more in the onlay group but this difference was not statistically significant. Ahmed reported similar results in his study on 110 cases of incisional hernia. Wound infection occurred in $8.1 \%$ of the onlay group and $4.3 \%$ of the sublay group ( $p=$ 0.465 ) [20]. Dhaigude et al., reported higher rates of wound infection $(26 \%$ and $12 \%$ in onlay and sublay groups repectively) [19]. In contrast, Saeed et al., found that wound infection was higher in 
the sublay group (10\%) while only $5 \%$ in the onlay group [18]

In our study, one patient in the sublay group $(1.7 \%)$ and 2 patients in the onlay group (3.3\%) had mesh infection necessitating its removal. The source of infection in the patient with sublay repair was intestinal perforation and enterocutaneous fistula formation that mandated reoperation in which resection of of the perforated small bowel segment containing the mesh involved in the perforation was done followed by primary anastomosis and complete excision of the remaining mesh. In the 2 patients with onlay repair the infection was transmitted from the subcutaneous tissue to the mesh. Mesh removal was done after failure of conservative management with antibiotics and local wound care. Hernia recurred after mesh removal in all the 3 cases. Dhaigude et al., reported mesh infection and removal in $6 \%$ of patients with the onlay repair and in $2 \%$ of patients with the sublay repair ( $p=0.307)$ [19]. In another study, Ahmed reported that mesh infection mandating its removal occurred in $3.2 \%$ of patients in the onlay group but did not occur in any patient in the sublay group $(p=0.504)$ [20]. Hernia recurrence is a distressing event to patient and embarrassing to surgeons. An incidence of about $1.5-10 \%$ of incisional hernia recurrence following open mesh repair was reported in the literature. Many studies of same interest compared the recurrence rate in onlay versus sublay repair and found higher incidence in case of onlay repair [14].

In the present study, hernia recurrence occurred in 3 cases of the onlay group (5\%) and in 1 case of the sublay group (1.7\%) during the 6 months follow-up period. Similar to our results, Dhaigude et al., found that there was no significant difference between the 2 groups regarding hernia recurrence. During 6 months of follow-up, recurrence occurred in $2 \%$ of the onlay group and none in the sublay group ( $p=0.500$ ) [19]. Ahmed reported significantly higher incidence of hernia recurrence after onlay repair $(8 \%)$ compared to only $2.1 \%$ after sublay repair $(p=0.05)$. The follow-up period was one year [20]. Previous studies have shown that 70$75 \%$ of recurrences develop within 2 years and 80 90\% develops within 3 years [21]. Our follow-up, therefore, is probably not long enough and we advise longer duration of follow-up in subsequent studies.

\section{Conclusion:}

Sublay mesh repair of incisional hernia is a good alternative to onlay repair. It is applicable to all sites of incisional hernia with a low recurrence rate and acceptable complication rates. It is our belief that the sublay repair is the preferred technique in treatment of incisional hernia compared to the onlay repair as it was superior in terms of less number of complications. However, we recommend carrying out further larger population studies with longer periods of follow-up for more accurate evaluation.

\section{References}

1- EL-SANTAWY H.M., EL-SISY A.A., EL-GAMMAL A.S., EL-KASED A.F. and SULTAN H.M.: Evaluation of retromuscular mesh repair technique for treatment of ventral incisional hernia. Menoufia Med. J., 27 (2): 2269, 2014.

2- SHELL D.H., De LA TORRE J., ANDRADES P. and VASCONEZ L.O.: Open Repair of Ventral Incisional Hernias. Surg. Clin. North. Am., 88 (1): 61-83, 2008.

3- LEITHY M., LOULAH M., GREIDA H.A., BAKER F.A. and HAYES A.M.: Sublay hernioplasty versus onlay hernioplasty in incisional hernia in diabetic patients. Menoufia Med. J., 27 (2): 353-8, 2014.

4- BHAT M. and SOMASUNDARAM S.: Preperitoneal mesh repair of incisional hernias: A seven-year retrospective study. Indian J. Surg., 69 (3): 95-8, 2007.

5- HOLIHAN J.L., NGUYEN D.H., NGUYEN M.T., MO J., KAO L.S. and LIANG M.K.: Mesh location in open ventral hernia repair: A systematic review and network meta-analysis. World J. Surg., 40 (1): 89-99, 2016.

6- AHMED M. and MEHBOOB M.: Comparisons of Onlay versus Sublay Mesh Fixation Technique in Ventral Abdominal Wall Incisional Hernia Repair. J. Coll. Physicians Surg. Pak., 29 (9): 819-22, 2019.

7- SEVINÇ B., OKU S A., AY S., AKSOY N. and KARAHAN Ö.: Randomized prospective comparison of long-term results of onlay and sublay mesh repair techniques for incisional hernia. Turk. J. Surg., 34 (1): 17-20, 2018.

8- KUMAR G.A., BEJJAMSHETTY N. and KUMAR R. A Clinical Study on Incisional Hernia: Anatomical Repair V/S Mesh Repair. Int. J. Sci. Study, 6 (6): 131-7, 2018.

9- VENCLAUSKAS L., MALECKAS A. and KIUDELIS M.: One-year follow-up after incisional hernia treatment: Results of a prospective randomized study. Hernia, 14 (6): 575-82, 2010.

10- SINGH B., JALTHANIA M.K. and KUMARI S.: A comparative study of various techniques of incisional hernia repair in a tertiary care center at Bikaner (North-West Rajasthan). Int. Surg. J., 6 (8): 2909-15, 2019.

11- KURZER M., KARK A., SELOUK S. and BELSHAM P.: Open mesh repair of incisional hernia using a sublay technique: Long-term follow-up. World J. Surg., 32 (1): 31-6, 2008.

12- KAPOOR K.K. and HASSAN M.M.: A clinical study of abdominal wound dehiscence with emphasis on surgical management in Bangalore medical college and research institute, Karnataka, India. Int. Surg. J., 4 (1): 134-40, 2017. 
13- GARG N., BATRA P. and BALI S.: The clinical study of the incisional hernia and its management. Int. Surg. J., 4 (7): 2281-7, 2017.

14- SABER A. and EMAD K.B.: Onlay versus Sublay Mesh Repair for Ventral Hernia. J. Surg., 4 (1-1): 1-4, 2015.

15- IBRAHIM A.H., EL-GAMMAL A.S. and HEIKAL M.M.: Comparative study between 'onlay' and 'sublay' hernioplasty in the treatment of uncomplicated ventral hernia. Menoufia Med. J., 28 (1): 11-6, 2015.

16- SHAH T.A., MODI Y.S., SUVERA M.S., PARMAR R.H., VAJA K.C., PATEL J.B., et al.: A comparative study of onlay and pre-peritoneal mesh repair in the management of ventral hernias in our hospital. J. Indian Med. Assoc., 117 (5): 25-8, 2019.

17- GODARA R., GARG P., RAJ H. and SINGLA S.L.: Comparative evaluation of "Sublay" versus "Onlay" meshplasty in ventral hernias. Indian J. Gastroenterol., 25 (4): 222-3, 2006.

18- SAEED N., IQBAL S.A., SHAIKH B.A. and BAQAI F.: Comparison between onlay and sublay methods of mesh repair of incisional hernia. J. Post. Med. Inst., 28 (4): 400-3, 2014.

19- DHAIGUDE B.D., SUGUNAN A., PANCBHAI S.V., FRANCIS M., PATEL K. and METTA V.: Comparative evaluation of sublay versus onlay meshplasty in incisional and ventral hernias. Int. Surg. J., 5 (1): 187-92, 2017.

20- AHMED H.A.: Evaluation of Sublay Mesh Repair in Comparison with Onlay Mesh Repair for Incisional Hernias. Iraqi Postgrad. Med. J., 15 (2): 180-4, 2016.

21- ALSOUDANY S.E., KHALIL O.O. and SHEBL A.M.: Comparative Study between "Onlay" Versus "Retrorectus" Hernioplasty in Management of Uncomplicated Venteral Hernias. Egypt J. Hosp. Med., 73 (4): 6423-30, 2018.

\section{دراسة مقارنة بين وضع الشبكة خلف عضلات جدار البطن وبين وضع الشبكة آمامها فى علاج الفتح حلف الجراحى}

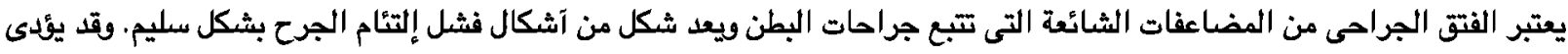

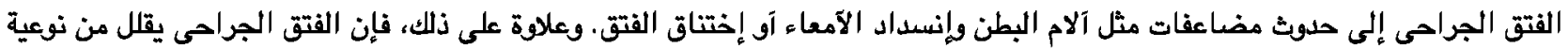

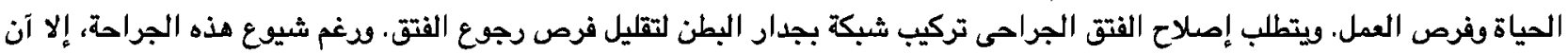
المكان الآمثل لوضرع الشبكة لا يزال محل جدال.

الهدف من الدراسة: هو المقارنة بين طريقة وضع الثبكة خلف عضلات جدار البطن وطريقة وضع الشبكة آمامها فى علاج حالات الفتق

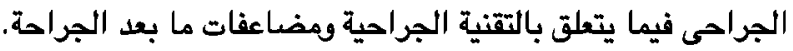

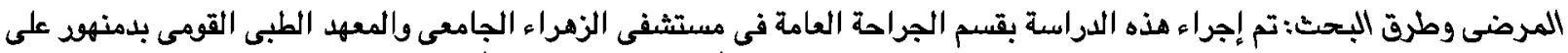

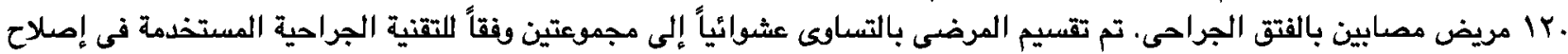

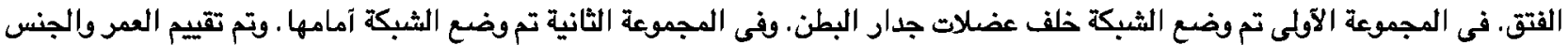

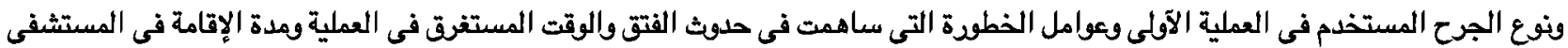

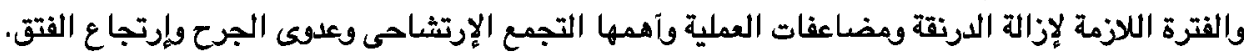

الخلاصة: يعد علاج الفتق الجراحى عن طريق وضع الشبكة خلف عضلات جدار البطن بديل جيد لطريقة وضع الثبكة آمام العضلات.

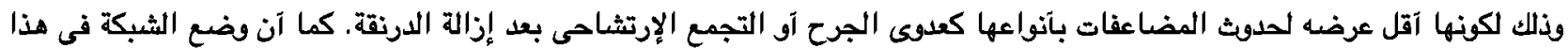

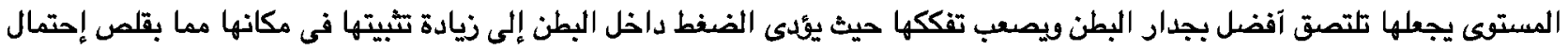
حدوث إرتجاع للفتق مرة ثانية. 